\title{
TIG PROCESSING OF NIMONIC 80A ALLOY FOR ENHANCED CAVITATION EROSION RESISTANCE
}

\author{
Cosmin Ion BELIN, Ion MITELEA, Ilare BORDEAŞU, Corneliu Marius CRĂCIUNESCU \\ Politehnica University of Timisoara, Timisoara, Romania, EU, \\ cosmin.belin@student.upt.ro, ion.mitelea@upt.ro, ilare.bordeasu@upt.ro, corneliu.craciunescu@upt.ro
}

https://doi.org/10.37904/metal.2019.920

\begin{abstract}
The surface of Nimonic 80A alloy was melted and rapidly solidified using TIG process (Tungsten Inert Gas) in order to produce a high-strength microstructure to improve cavitation erosion resistance. Cavitation tests, performed on an ultrasonic vibrator at a frequency of $20 \mathrm{kHz}$ and at amplitude of $50 \mu \mathrm{m}$ oscillations pointed out that these microstructure changes lead to significant differences in the behavior of this alloy to erosion generated by vibrator cavitation. Optical microscopy and scanning electron microscopy of the TIG melted sample surface and tested for cavitation erosion, showed a ductile behavior. At the same time, the finishing of the microstructure is showing a significant decrease of the maximum erosion penetration depth and of the erosion speed compared to the reference material.
\end{abstract}

Keywords: Nimonic 80A alloy, TIG melted surface, structure, cavitation

\section{INTRODUCTION}

Cavitation is the process of formation, growth and implosion of bubbles containing vapors, gases or a mixture of gas vapors due to cyclic pressure changes in the flowing liquid [1]. Cavitation implosion is an effect of changing the pressure from the low-value zone to a high pressure region, causing condensation of vapors that fill the cavity bubbles. The implosion phenomenon occurs at a very high speed (exceeding $100 \mathrm{~m} / \mathrm{s}$ ), and the growth and degradation time of the cavitation bubble is in the order of milliseconds [1-3].The dynamics of bubble formation and collapse is dependent on the physico-chemical properties of the fluid and the distance between the wall and the bubble interaction site. In the vicinity of the wall, an implosion of bubbles is formed, which can reach speeds of 300 to $500 \mathrm{~m} / \mathrm{s}$. Microcurrents formed during cavitation bubble impulse transmit pressure walls to the walls of the order of $1 \div 4 \mathrm{GPa}$. The multiple repetition of the cavitation implosion causes the destruction of the material $[4,5]$.

Nickel-based alloys are building materials characterized by a very high mechanical strength and high corrosion resistance [5]. Following the properties offered, they are used in the construction of aircraft gas turbines, steam turbine power plants, nuclear power systems, chemical and petrochemical industries. Such products work in extreme conditions and are exposed to corrosive phenomena in aggressive environments and erosion caused by cavitation. The Nimonic $80 \mathrm{~A}$ alloy is designed for the execution of gas turbine components (blades, discs, fasteners, etc.) and exhaust valves of reaction engines and high performance internal combustion piston engines where the pressure and heat are extreme. In recent years, high-energy beams, such as electrons, laser beam [6,7], and plasma arc, have been tried to alter the physical state of the metal alloy surface. By such techniques, the surface of the material is remelted, and by rapid solidification there is a microstructure finishing and, implicitly, an improvement in wear resistance. Due to the high cost of operating laser equipment and the need for vacuum in electron beam chambers, our attention has been focused on the use of cheap, flexible and easy-to-operate welding machines for Nimonic 80A alloy surface melting treatments.

The TIG electric arc produces sufficient heat energy to be useful for both metal alloy melting and surface treatments [8, 9]. In addition, this process offers several significant advantages including selective hardening, minimal track distortion, controllable depth of the modified layer, and lack of a cooling agent. 
The present paper proposes the use of the TIG process as a heating source to alter the surface of a nickel base alloy by local remelting and to achieve an improvement in vibration cavitation behaviour.

\section{INVESTIGATED MATERIAL, EXPERIMENTAL STAND AND WORKING PROCEDURE}

The investigated material is the Nimonic 80A alloy (EN NiCr20TiAl; UNS No 7080; W. No. 24952 \& 24631) having the following chemical composition: $20.5 \mathrm{wt} \% \mathrm{Cr}, 1.98 \mathrm{wt} \% \mathrm{Ti}, 1.54 \mathrm{wt} \% \mathrm{Al}, 2.14 \mathrm{wt} \% \mathrm{Fe}, \mathrm{Mn}, 0.48$ wt $\% \mathrm{Si}, 0.12 \mathrm{wt} \% \mathrm{Cu}, 0.08 \mathrm{wt} \% \mathrm{C}, 0.014 \mathrm{wt} \% \mathrm{~S}, 0.11 \mathrm{wt} \% \mathrm{Zr}$, rest Ni.

The main alloying element is chromium, which improves the resistance to hot oxidation. Additions of aluminium and titanium further promote the hardening of the alloy by aging. The best properties of Nimonic alloys are obtained by applying solution heat treatment followed by artificial aging (Figure 1).

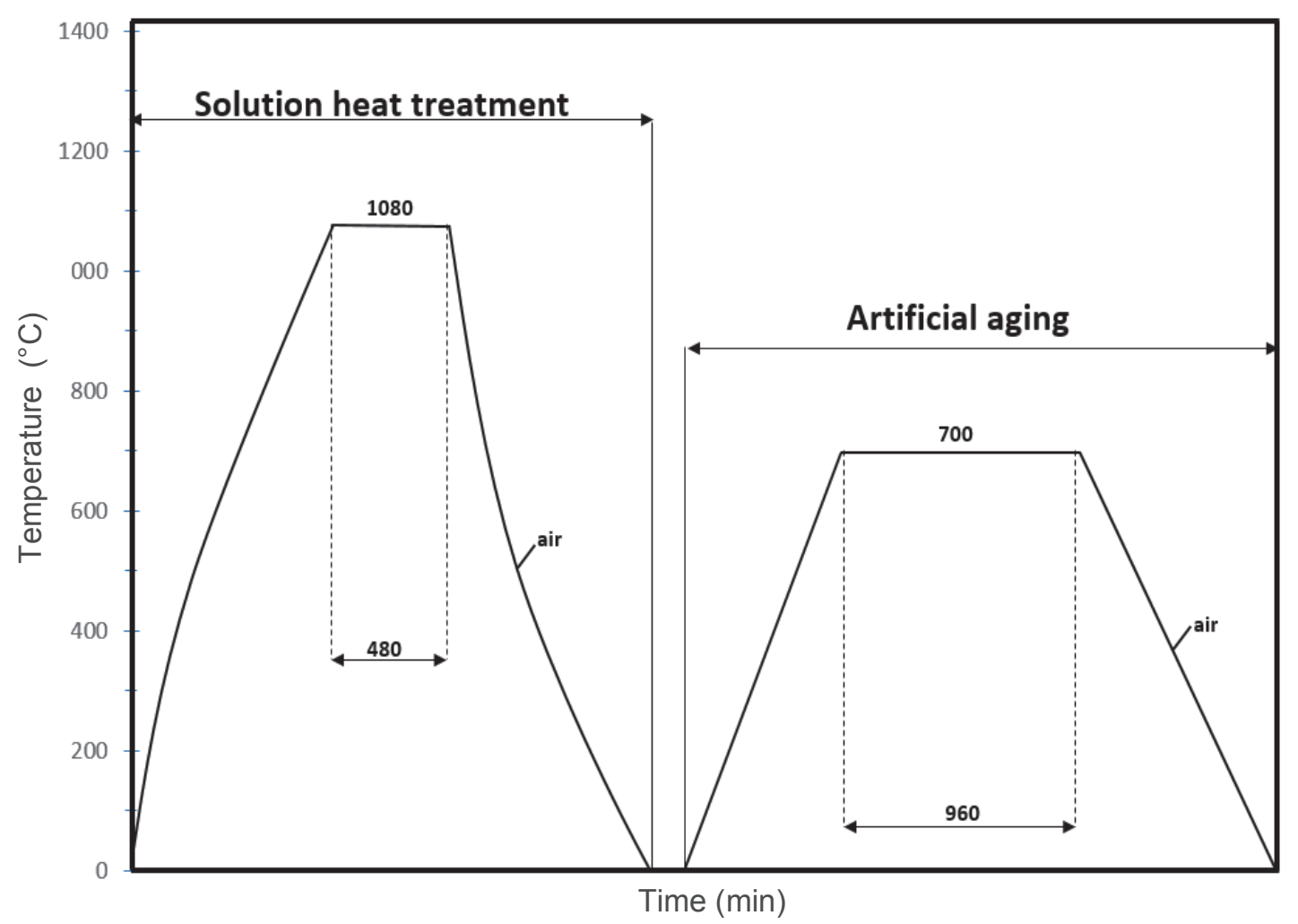

Figure 1 Heat treatment cycle

Cavitation samples were obtained from cylindrical rolled bars, $\varphi 20 \times 300 \mathrm{~mm}$, subjected to this thermal treatment [6]. Subsequently, some of these samples underwent a TIG remelting of the surface to support the flow of water.

Cavitation tests were conducted on a piezoceramic vibrator [6] with piezoceramic crystals (Figure 2) made in accordance with the requirements of ASTM G32-2010. Its functional parameters are: power $500 \mathrm{~W}$; vibration frequency $20000 \mathrm{~Hz}$; vibration amplitude $50 \mu \mathrm{m}$; sample diameter $15.8 \mathrm{~mm}$; supply voltage $220 \mathrm{~V} / 50 \mathrm{~Hz}$; working fluid temperature $22 \pm 1{ }^{\circ} \mathrm{C}$.

The total duration of each test was 165 minutes and was divided into 12 intermediate periods (one for 5 and 10 minutes and 10 for 15 minutes each).

At the beginning and end of each test period, the samples were washed under a jet of water (grid), distilled water, alcohol, acetone, dried under hot air and weighed. 


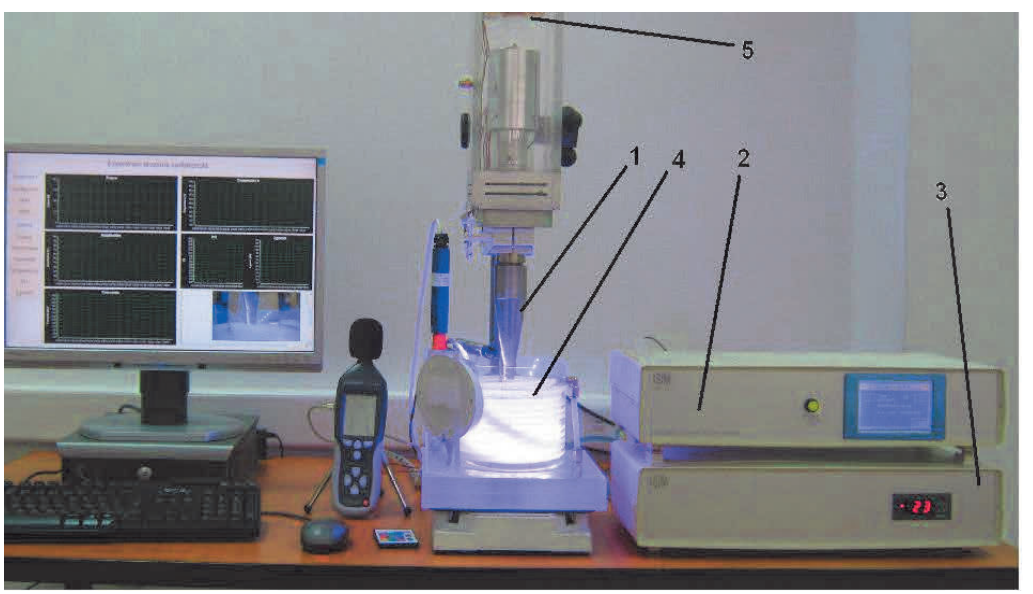

Figure 2 Ultrasonic vibrator device with piezoceramic crystals: 1- sonotroda; 2 - electronic system; 3 -water temperature regulator; 4 - liquid container with cooling coil; 5 - ventilation system

Prior to testing and at the end of each interim test period, the surfaces exposed to the cavity were examined under the optical microscope and photographed with the high resolution Canon Power Shot A480 camera to track the evolution of surface destruction exposed to the attack.

Samples were weighed before the tests began and at the end of each intermediate period. Weighing is done with an analytical balance, the accuracy of which is 5 significant decimals (up to 0.00001 grams). At the end of each intermediate test period " $i "$, determine the corresponding mass loss $\Delta m_{i}$.

Eroded mass was determined with the relation: $m_{i}=\sum_{i=1}^{12} \Delta m_{i}$

Based on the mass losses, the erosion rate values were determined.

\section{RESULTS AND DISCUSSIONS}

Figures 3 and $\mathbf{4}$ show the variation curves of mass losses and erosion speed with attack time.

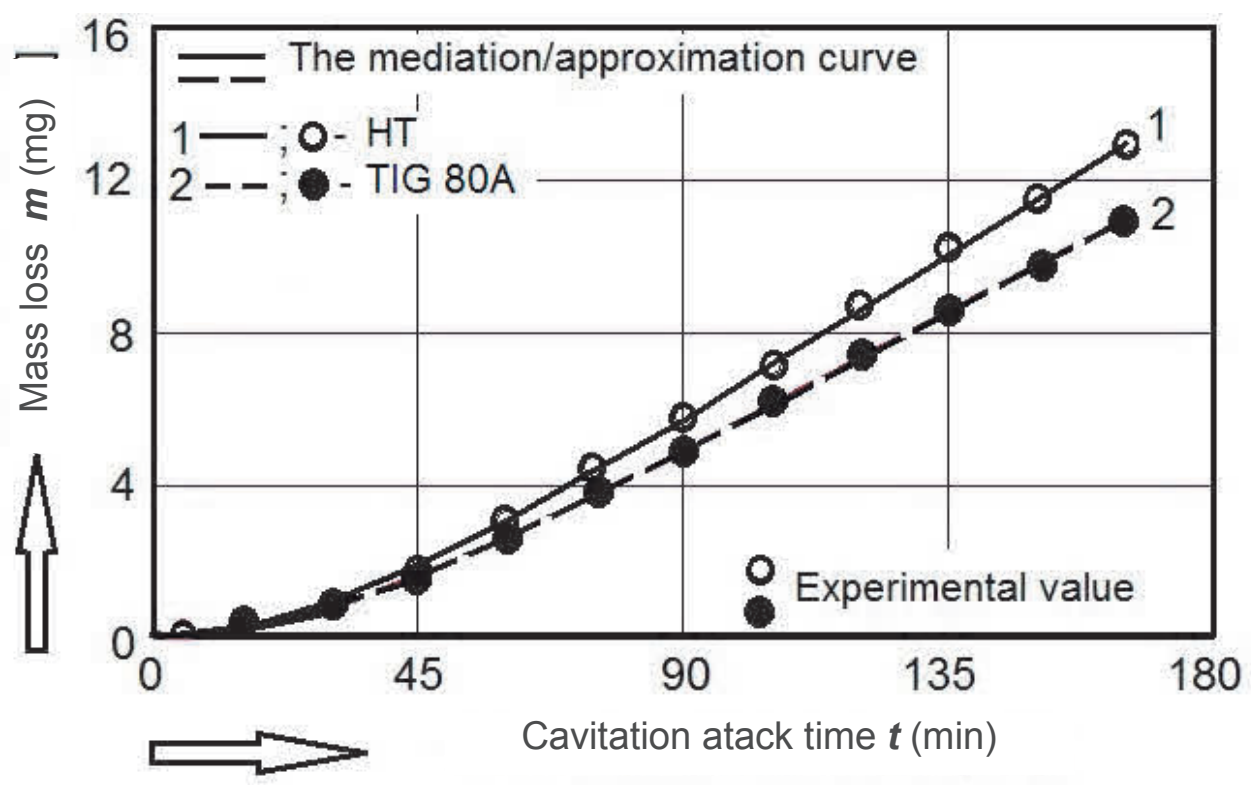

Figure 3 Evolution of mass loss with attack time: 1 - HT - heat treatment; 2 - TIG Remelting with 80 A 


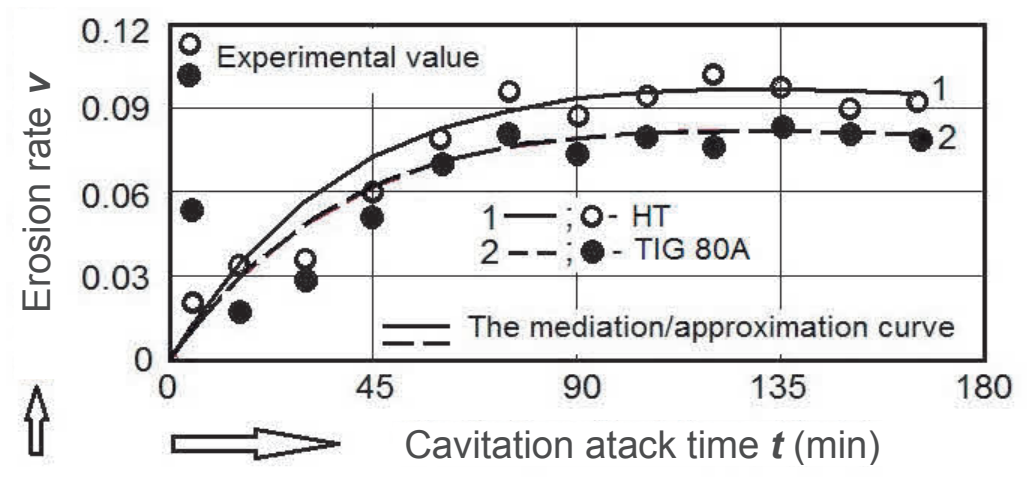

Figure 4 Rate of erosion speed with attack time: 1 - HT - heat treatment; 2 - TIG Remelting with 80 A

The approximation of experimentally obtained values for mass losses (Figure 3 ) and the evolution of erosion rate over time (Figure 4), with the tendency to stabilize the erosion velocity at the maximum value, shows that the two states structural properties of the studied material provide a very good behavior to erosion through vibratory cavitation generated by the device used. At the same time, it is appreciated that this mode of behavior is due to the homogeneity and high degree of finishing of the surface layer structure exposed to the attacks of the cavitation microjet. The dispersion of the experimental values of the erosion rate (Figure 4), compared to the mediation curves, is lower for the state obtained by TIG remelting (curve 2), compared to that obtained in the samples subjected to the solution heat treatment followed by artificial aging (curve 1); this shows that the resistance and cavitation behavior of the TIG melted surface is superior.

Examining by the optical microscope and the scanning electron microscope of the sample surface tested at ultrasonic vibratory cavitation shows that the f.c.c crystalline matrix structure of the Nimonic alloy, which has a large number (12) of plastic deformation sliding systems, is proves to be an extremely beneficial parameter against cavitation erosion (Figure 5). Previous research papers [2, 6] reported that austenitic stainless steels, the interface between chromium carbides and austenite are associated with intense stresses.

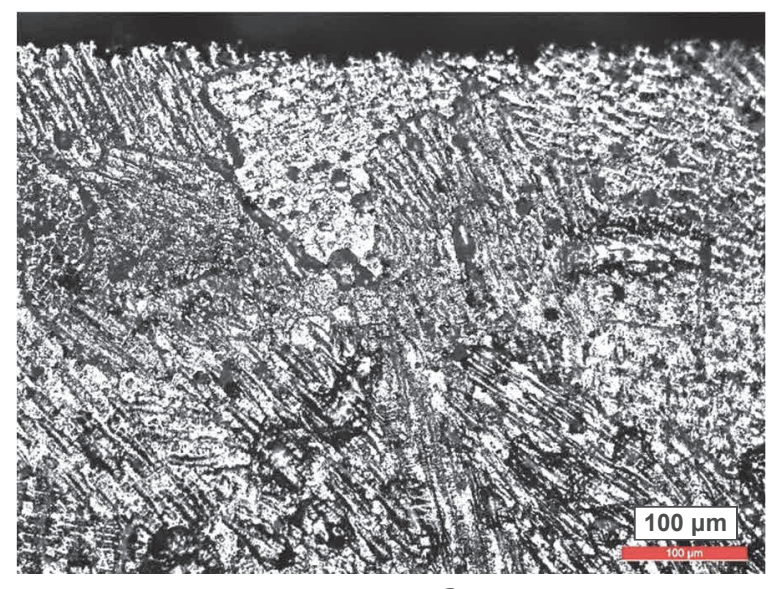

a

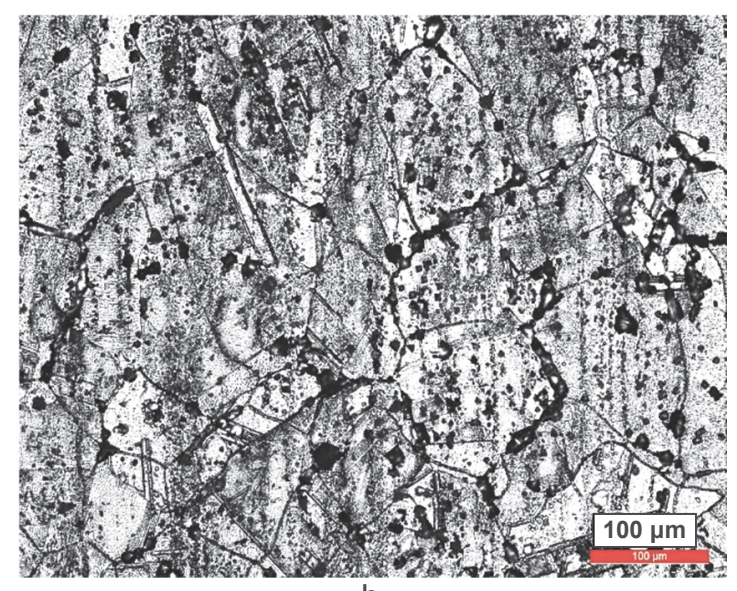

b

Figure 5 Microstructure of the cavitation tested sample for: a) 165 min eroded sample; b) base material

The same phenomenon occurs in the Nimonic alloy, where the interface between the $y$ solid solution matrix and the secondary phase particles is attacked more strongly compared to the grains of the structural matrix f.c.c. The interfaces can not be mechanically hardened and, consequently, become fragile and fracture by cavitation attack; at the same time, the localized resistance of the structural matrix increases with the degree of cold deformation during cavitation erosion. This explains why the grain boundaries are attacked more in comparison with the grains of the $y$ solid solution in the alloy under investigation. Granulation finishing and limiting secondary phase precipitation following TIG surface remelting, increases the absorption capacity of 
cavitation impact wave energy, which delays nucleation of cracks. From Figure 6 it can be seen that in the first 15 minutes of testing, the surface of the samples does not undergo any modification, after which, until the minute 105, the traces of the melted rows are visible successively and until the end of the test there is practically a uniformization of material removal on the entire surface.

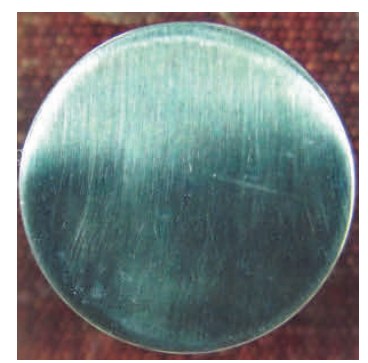

$0 \min$

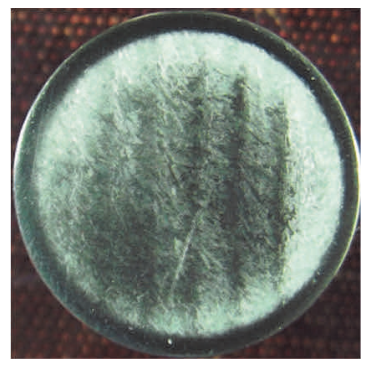

$45 \mathrm{~min}$

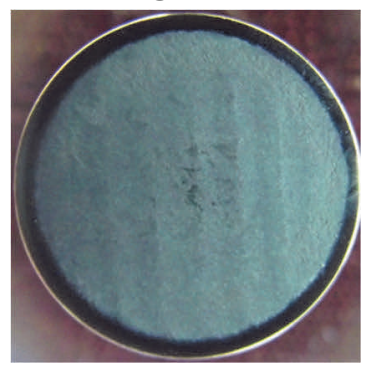

$105 \mathrm{~min}$

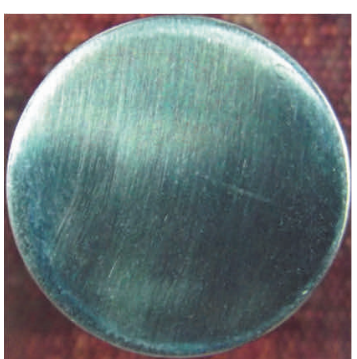

$5 \min$

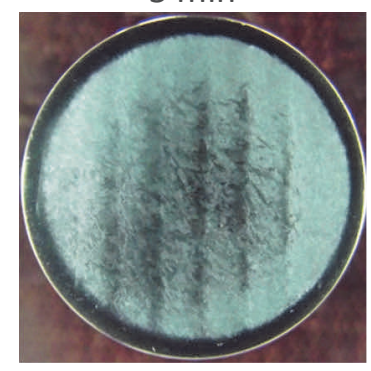

$60 \mathrm{~min}$

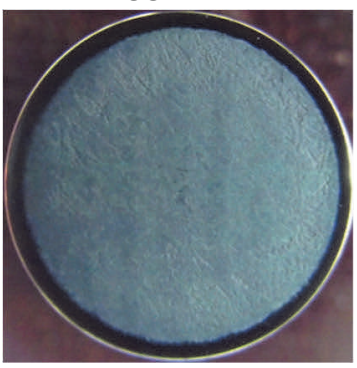

$120 \mathrm{~min}$

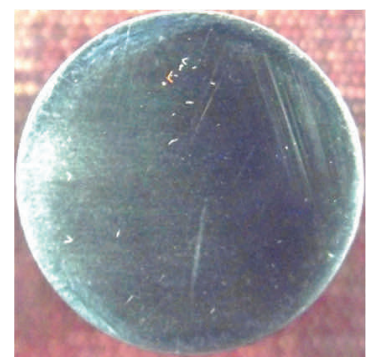

$15 \min$

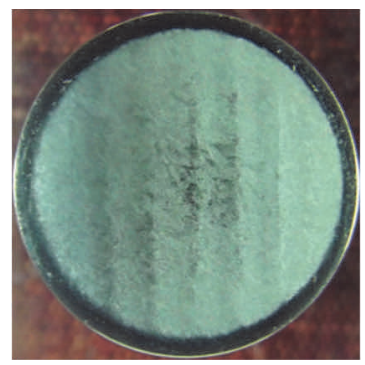

75 min

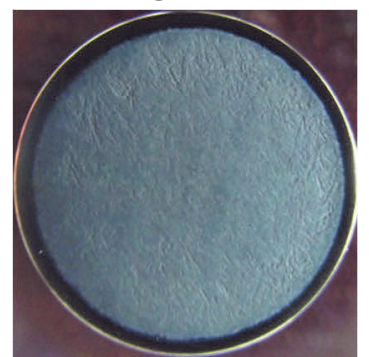

135 min

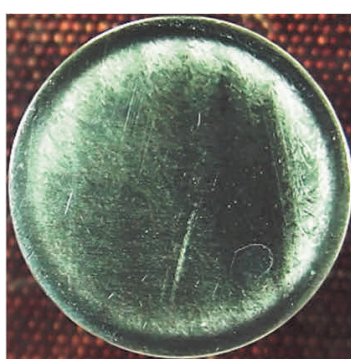

$30 \mathrm{~min}$

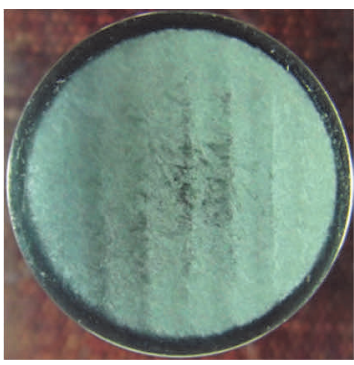

$90 \mathrm{~min}$

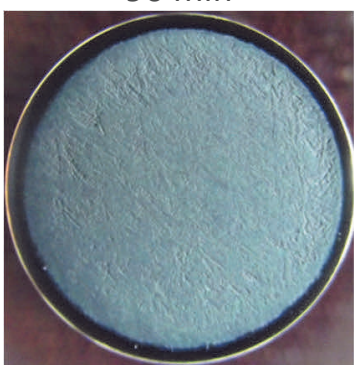

$150 \mathrm{~min}$

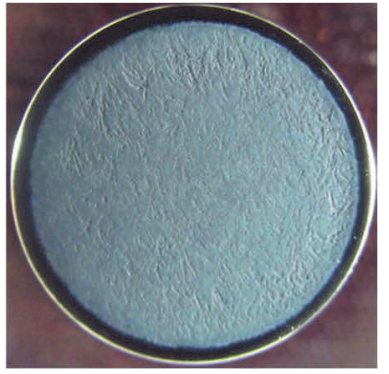

$165 \mathrm{~min}$

Figure 6 Macrographic images of the surface of remelted TIG samples (diameter $15.8 \mathrm{~mm}$ ), tested at variable cavitation time

\section{CONCLUSIONS}

Cavitation erosion resistance of the remelted alloy with a TIG source is greater than that obtained by applying conventional solution treatment followed by artificial aging. However, regardless of the thermomechanical processing state, the Nimonic alloy exhibits excellent resistance to cavitation erosion.

From microstructure point of view, the grain boundaries that are associated with the internal stresses are less able to absorb the deformation energy due to the transient stresses from the material induced by the cavitation 
impact waves erode faster than the $y$ solid solution structure. It can also be inferred that the secondary phases present in the alloy worsen the erosion resistance of the cavitation. Limiting the proportion of such phases in the TIG remelted layer provides greater cavitation erosion. For both heat processing conditions, damages caused by cavitation erosion occur along the grain boundaries, and the secondary phases are the first to be dislodged from the structure of the material.

\section{REFERENCES}

[1] FRANE, J.-P. and MICHEL, J.M. Fundamentals of Cavitation. Kluwer Academic Publishers. Dordrecht - Boston London. 2004. p. 81-127.

[2] NIEDERHOFER, P. and HUTH, S. Cavitation erosion resistance of high interstitial CrMnCN austenitic stainless steels. Journal Wear. 2013. vol. 301, no. 1-2, pp. 457-466.

[3] BENYOUNIS, K.Y., FAKRON, O.M.A., ABBOUD, J.H., OLABI, A.G., HASHMI, M.J.S. Surface melting of nodular cast iron by Nd-YAG laser and TIG. J Mater Process Technol, 170 (2005), pp. 127-132

[4] KRELLA, A. K. and KRUPA, A. Effect of cavitation intensity on degradation of X6CrNiTi18-10 stainless steel. Journal Wear. 2018, vol. 408-409, pp. 180-189.

[5] BELIN, C., MITELEA, I., BORDEASU, I. and CRACIUNESCU, C.M. On surface topography and microstructure in cavitation erosion tests of alloy $80 \mathrm{~A}$. In 7th International Conference on Advanced Materials and Structures AMS 2018. IOP Conf. Series: Materials Science and Engineering. 2018. vol. 416. p. 012010. doi:10.1088/1757899X/416/1/012010

[6] MITELEA, I., MICU, L.M., BORDEASU, I. and CRACIUNESCU, C.M. Cavitation Erosion of Sensitized UNS S31803 Duplex Stainless Steels. Journal of Materials Engineering and Performance. 2016. vol. 25, no. 5, pp. 1939-1944.

[7] ALABEEDI, K.F., ABBOUD, J.H. and BENYOUNIS, K.Y. Microstructure and erosion resistance enhancement of nodular cast iron by laser melting. Journal Wear. 2009. vol. 266, pp. 925-933.

[8] LO, K. H., KWOK, C. T., WANG, K. Y. and WENJI, A.I. Implications of solution treatment on cavitation erosion and corrosion resistances and synergism of austenitic stainless steel. J. Wear. 2017. vol. 392-393, pp. 159-166.

[9] HU, H. X., GUO, X. M. and ZHENG, Y. G. Comparison of the cavitation erosion and slurry erosion behavior of cobalt-based and nickel-based coatings. J. Wear. 2019. vol. 428-429, pp. 246-257. 